\title{
A REPRESENTAÇÃO DE MULHERES NEGRAS NA LITERATURA AFRO-BRASILEIRA: UMA LEITURA DE "A ESCRAVA", DE MARIA FIRMINA DOS REIS E "MINHA MÃE", DE LUIS GAMA
}

\section{THE REPRESENTATION OF BLACK WOMEN IN AFRO-BRAZILIAN LITERATURE: A READING OF "A ESCRAVA", DE MARIA FIRMINA DOS REIS AND "MINHA MÃE", DE LUIS GAMA}

Tatiana Valentim Mina Bernardes

Universidade Federal de Santa Catarina

Florianópolis, Santa Catarina, Brasil

Zâmbia Osório dos Santos

Universidade Federal de Santa Catarina

Florianópolis, Santa Catarina, Brasil

Eliane Santana Dias Debus

Universidade Federal de Santa Catarina

Florianópolis, Santa Catarina, Brasil

Resumo: Este artigo busca estudar a literatura afro-brasileira produzida no século XIX, em particular o conto "A escrava", de Maria Firmina dos Reis, e o poema "Minha mãe", de Luís Gama, verificando como ambos os textos, publicados em 1859, embora em gênero distintos, tematizam e representam a mulher negra. Ao adentrarmos nessa discussão, algumas considerações se fazem importantes no que diz respeito ao conceito de literatura afro-brasileira e, para isso, apoiamo-nos no referencial teórico de Eduardo Assis Duarte (2010, 2011). As representações de mulheres negras em "A escrava" e "Minha mãe", Joana e a mãe do escritor Luís Gama, frutos de uma escrita afro-brasileira, são construídas pelas vivências desses escritores, que desafiam a lógica das representações que circulavam pela sociedade da época acerca da população negra, desafio esse que produz narrativas necessárias em nossa sociedade, onde construções sociais baseadas no racismo se mantém de forma estrutural, por isso também a importância dessa discussão nos espaços escolares.

Palavras-chave: Literatura afro-brasileira; Mulher; Maria Firmina dos Reis; Luís Gama

\begin{abstract}
This article aims to study the Afro-Brazilian literature produced in the 19th century, in particular the short story "A esclrava" by Maria Firmina dos Reis, and the poem "Minha mãe" by Luís Gama, verifying how both published texts in 1859, although in distinct genres, they thematize and represent the black woman. As we enter into this discussion,
\end{abstract}


some considerations become important with regard to the concept of Afro-Brazilian literature, and for this, we rely on the theoretical framework of Eduardo Assis Duarte (2010, 2011). The representations of black women in "A slave" and "My mother," Joana and the mother of the writer Luís Gama, fruits of Afro-Brazilian writing, are built by the experiences of these writers, who challenge the logic of representations that circulated through society of the time about the black population, a challenge that produces necessary narratives in our society, where social constructions based on racism are maintained in a structural way, therefore also the importance of this discussion in school spaces.

Keywords: Afro-Brazilian literature; Woman; Maria Firmina dos Reis; Luis Gama 
Este artigo busca estudar a literatura afro-brasileira produzida no século XIX, em particular o conto "A escrava", de Maria Firmina dos Reis (2004), e o poema "Minha mãe", de Luís Gama (2000), verificando como ambos os textos, publicados em 1859, embora em gênero distintos, tematizam e representam a mulher negra. Ao adentrarmos nessa discussão, algumas considerações se fazem importantes no que diz respeito ao conceito de literatura afro-brasileira.

Para Eduardo de Assis Duarte (2010), a necessidade de trazer esse conceito à cena, centra-se, principalmente, no silenciamento da literatura realizada por anos pelas populações negras, no conjunto da literatura universal, consequência, por certo, de uma lógica racista que organiza a sociedade e suas relações, selecionando o conhecimento, a memória e a história, narrada por críticos literários inseridos nesse contexto

A Literatura Afro-brasileira, conforme o autor, faz-se presente já no século XVIII e palmilha passo a passo o seu trajeto na cena literária contemporânea, sendo produzida em diferentes espaços geográficos do Brasil, propulsora de uma força que "[...] se faz presente nos espaços históricos de nossa constituição enquanto povo; não só existe como é múltipla e diversa" (DUARTE, 2010, p. 113). Ainda argumenta que a produção de escritores afro-brasileiros se amplia a partir de 1980, ocupando espaço na arte cultural, ao mesmo tempo em que as demandas do movimento negro se expandem e ganham evidência institucional. Aliada a essa expansão, mas com menos amplitude, crescem paulatinamente as produções acadêmicas sobre a Literatura Afro-brasileira escrita por escritores afro-brasileiros.

$\mathrm{O}$ termo afro-brasileiro é designado tanto às pessoas com descendência africana quanto para os artefatos, as manifestações, as tradições e a cultura provenientes da vinda dos africanos escravizados no Brasil. Duarte (2010, p. 119, grifo do autor) define que:

[...] o termo afro-brasileiro, por sua própria configuração semântica, remete ao tenso processo de mescla cultural em curso no Brasil desde a chegada dos primeiros africanos. Processo de hibridismo étnico e linguístico, religioso e cultural. De acordo com um pensamento conservador, poder-se-ia dizer que afrobrasileiros são também todos os que provêm de ou pertencem a famílias mais antigas, cuja genealogia remonta ao período anterior aos grandes fluxos migratórios ocorridos desde o século XIX. E, como este, outros reparos poderiam ser arrolados, dado o caráter não essencialista do termo.

Dessa forma, podemos definir que a Literatura Afro-brasileira provém da escrita literária de pessoas que se autodeclaram e se identificam como afrobrasileiros, diferenciando-se da escrita de escritores brancos que escrevem sobre os negros. Embora o pesquisador reconheça que seja um conceito em construção, ele destaca cinco identificadores da Literatura Afro-brasileira que a distingue, a saber: temática, autoria, ponto de vista, linguagem e público. 
Para além das discussões conceituais, alguns identificadores podem ser destacados: uma voz autoral afrodescendente, explícita ou não no discurso; temas afro-brasileiros; construções linguísticas marcadas por uma afro-brasilidade de tom, ritmo, sintaxe ou sentido; um projeto de transitividade discursiva, explícito ou não, com vistas ao universo recepcional; mas, sobretudo, um ponto de vista ou lugar de enunciação política e culturalmente identificado à afrodescendência, como fim e começo. Alertando para o fato de que se trata de um conceito em construção, passamos a examinar mais detidamente cada um desses elementos. (DUARTE, 2010, p. 122, grifo do autor).

Assim, a Literatura Afro-brasileira é definida aqui como a produção literária voltada à autoria, ao sujeito negro falando de si e dos seus, considerações que propomos neste artigo ao dialogarmos com a produção literária de Maria Firmina dos Reis e Luís Gama e a representação de mulheres negras nas suas obras. A escolha por visibilizar representações de mulheres negras ocorre por compreendermos que há um papel fundamental das estruturas sociais e conjunturas históricas na constituição das representações, já que as ideias que fundamentam percepções sobre as coisas, as pessoas ou os processos são produzidas socialmente. As coletividades produzem representações, algumas se traduzem em homogeneidade de pensamentos, outras escapolem do lugar comum e renovam a possibilidade de ver o Outro.

O debate sobre autoria é muito caro para nós, principalmente para entender como representações tão distintas podem ocorrer de um mesmo tema a partir das vivências de quem está construindo a narrativa literária. Diante disso, voltamonos, agora, para uma breve apresentação dos escritores escolhidos, Maria Firmina dos Reis e Luís Gama, para dialogar sobre representação de mulher negra na literatura afro-brasileira, a partir de algumas informações que consideramos importante conhecer sobre suas vidas.

\section{Nossas escolhas}

Maria Firmina dos Reis, mulher negra, nasceu na ilha de São Luís, capital da então província do Maranhão, região nordeste do Brasil, em 11 de outubro do ano de 1825. Primeira romancista brasileira e uma das primeiras de língua portuguesa, esteve fortemente engajada ao movimento abolicionista. Filha de João Pedro Esteves, homem negro, e de Leonor Felipe dos Reis, mulher branca, mudou-se muito pequena, com cinco anos de idade, para a vila de São José de Guimarães, onde foi criada pela tia, já que não fora fruto de um casamento.

Em 1847, prestou concurso para cadeira de Instrução e se tornou professora concursada para a "Cadeira de Instrução Primária" na então comarca de Guimarães, no interior do Maranhão, onde lecionou de 1847 a 1881, nos jornais oficiais do Maranhão é possível encontrar registros sobre suas turmas escolares, demonstrando sua participação ativa no processo de instrução de 
estudantes mulheres e homens. Ela foi responsável pela fundação, em 1880, da primeira escola mista, para meninos e meninas, no Maranhão.

Segundo Silva (2011), a escritora era conhecida pelos maranhenses do seu tempo pelo seu exercício no magistério, por isso seus textos circulavam pelos jornais daquele estado. No entanto, constata-se que houve um silenciamento de sua produção literária e, assim, ficamos tantos anos da história da literatura sem registro de sua escrita. Seu romance Úrsula (REIS, 2017) foi publicado em 1859, com o pseudônimo de "Uma Maranhense". Romance de cunho abolicionista leva o nome da personagem Úrsula, mas, conforme se nota, no tratamento dado às personagens negras e negros, às mulheres e à escravidão, percebemos que as preocupações centrais no romance são outras, para além da história de amor entre Úrsula e o bacharel Tancredo.

Para além das publicações de poemas e charadas em diversos jornais da época, em 1861, autora publica "Gupeva". Nessa narrativa ela se dedica a pensar o lugar destinado ao índio na sociedade brasileira, em 1887 traz a público o conto "A escrava". A escritora também é autora de uma letra do hino de libertação dos escravizados no Maranhão, o qual hoje se encontra apenas um fragmento (DUARTE, 2017).

No jornal $A$ Moderação, do dia 11 de agosto de 1860 , podemos ler a seguinte notícia sobre a venda do romance Úrsula:

ÚRSULA - Acha-se à venda na Tipografia do progresso, este romance original brasileiro, produção da Exma. Sra. Da. Maria Firmina dos Reis, professora pública em Guimarães. Saudamos a nossa comprovinciana pelo seu ensaio que revela de sua parte bastante ilustração; e, com mais vagar emitiremos a nossa opinião, que desde já afiançamos não será desfavorável á nossa distinta comprovinciana.

No prefácio do romance, Maria Firmina dos Reis faz um pedido de desculpas "Sei que pouco vale este romance, porque escrito por uma mulher, e mulher brasileira, de educação acanhada e sem o trato e conversação dos homens ilustrados" (REIS, 2017, p. 25). Entendemos, então, que a escritora tinha a compreensão de que o lugar que tentava ocupar no mundo das letras, com o reconhecimento de seus pares e aceitação social, era de difícil acesso para as mulheres, como bem caracterizou Silva (2011, p. 13), em que a morfologia do termo "palavra", no século XIX contrariava a gramática, sendo masculina, restando às mulheres o silêncio, mas esse silêncio era muito mais um movimento de silenciamento das produções do que fato a ausência das mesmas. A escritora faleceu em 11 de novembro de 1917, na Vila de Guimarães, interior da província, para onde foi quando criança.

Sobre o escritor Luís Gonzaga Pinto da Gama, encontra-se uma quantidade maior de informações, mas muitas oriundas de carta que ele escreve aos 50 anos em que narra a história de sua infância e juventude, explica a origem materna teria vindo da Costa da Mina -, escreve sobre a perda da mãe, o convívio com o pai que o vende na condição de escravizado e as dificuldades enfrentadas na juventude. 
Nascido em 21 de Junho de 1830 em Salvador, na Bahia, filho de africana livre e de homem branco de origem portuguesa. Aos sete anos de idade, no ano de 1837, perde contato com a mãe, Luísa Mahin, que se envolve na revolta de Sabinada e deixa a cidade de Salvador rumo ao Rio de Janeiro. No dia 10 de novembro de 1840, Luís Gama, com 10 anos de idade, é vendido escravizado pelo seu pai, para saldar dívidas de jogo (BRAZ, 1991). Assim, o menino é encaminhado ao traficante Vieira na cidade do Rio de Janeiro, que o vende ao Alfares Antônio Pereira Cardoso, fazendeiro de Lorena, província de São Paulo. $\mathrm{Na}$ casa de Antônio Pereira Cardoso, aprendeu a lavar, costurar e engomar roupas, e ainda exerceu o ofício de sapateiro e copeiro. Em 1847, conheceu e tornou-se amigo de Antônio Rodrigues do Prado, um jovem do interior São Paulo, que veio a capital estudar e hospedou-se na casa de Cardoso. Antônio Rodrigues do Prado ensinou Luís Gama a ler e escrever.

Em 1848, Luís Gama consegue provar nos tribunais que é um homem livre e foge da casa do alferes Cardoso, nesse ano entra para a Polícia Militar e permanece até 1854 , chegando a ser promovido a cabo da esquadra.

Até o ano de 1858 serve de escrivão às autoridades policiais. Nesse período trabalha no gabinete do Conselheiro Furtado de Mendonça, delegado de polícia e mestre da Faculdade de Direito, assim, consegue acesso à Biblioteca do Conselheiro e também entrada na Biblioteca da Faculdade de Direito, possibilitando a pesquisa e o conhecimento de todo acervo, desenvolvendo uma formação autodidata e intelectual sobre os aspectos e elementos que compõem a área jurídica e áreas gerais.

No ano de 1856, período conservador escravocrata, é nomeado copista da Secretaria de Polícia, mas acusado de indisciplinado e insurgente, foi exonerado. Luís Gama filia-se ao Partido Liberal e começa a atuar em causas abolicionistas e ações contra a Monarquia.

Em 1859, publica o livro de poesias, Primeiras Trovas Burlescas, inaugurando uma veia satírica ao gênero. Não conseguiu cursar a faculdade de Direito, mas se tornou um advogado provisório e um causídico conceituado e admirado nos tribunais de São Paulo e, a partir de 1860, volta seu trabalho às causas da liberdade, buscando na legislação e nos seus conhecimentos jurídicos a libertação dos negros escravizados, tornando-se um Republicano e Abolicionista.

Foi um pioneiro na história da imprensa paulistana, atuando ao lado de Ângelo Augostine em dois Jornais que foram os primeiros Periódicos Ilustrados da cidade de São Paulo, o Diabo Cocho, que circulou entre os anos de 1864 e 1865, e o Cabrião, de1865 e 1867, com a participação de outros jornalistas, como Américo de Campos. Assim, utiliza-se de todos os subterfúgios midiáticos da época para auxiliá-lo nas causas abolicionistas. O título de advogado foi concedido a Luís Gama 133 anos após a sua morte quando a Ordem dos Advogados do Brasil Nacional, juntamente com a Secional Paulista, outorgaramlhe o título pelos seus grandes feitos.

Luís Gama foi casado com Claudina Fortunata Sampaio e dessa união tiveram um filho, Benedito Graco Pinto da Gama. No dia 24 de agosto de 1882, aos 52 anos, morre de diabetes. Tendo liberado mais de 500 pessoas escravizadas ao longo de sua vida profissional, sua morte causou uma comoção na cidade de 
São Paulo, e seu corpo foi acompanhado por uma grande multidão, que admirava e respeitava seus feitos.

Seguindo a trilha da trajetória de Maria Firmino dos Reis e Luís Gama, apresentamos, a seguir, a produção literária de ambos e, em particular, aquela com foco da leitura aqui proposta.

\section{A representação da mulher negra nos textos de Maria Firmina dos Reis e Luís Gama}

Narrativas como as que nos propomos a analisar neste artigo são importantes tanto nas instituições de formação de educadores como na formação de estudantes, onde discursos estão em constante disputa de espaço. Em vista disso, há uma construção social sobre o que é "a mulher negra", existindo no singular, em verdade a construção é de dois "gêneros" de mulher negra: a mulata e a preta.

A mulata tem a materialização de sua representação na figura da mulher fogosa, fruto da mistura proibida do branco com a negra, detentora de toda libido tropical; enquanto a preta é a força bruta, da labuta diária, trabalhando lado a lado dos homens negros no eito ou no espaço da cozinha. Essa divisão é apresentada na literatura, de forma literal, por Gilberto Freyre (2003, p. 36), homem branco ${ }^{1}$, em Casa grande e senzala: "Com relação ao Brasil, que o diga o ditado: 'Branca para casar, mulata para f..., negra para trabalhar'; ditado em que se sente, ao lado do convencialismo social da superioridade da mulher branca e da inferioridade da preta, a preferência sexual pela mulata".

Essa mulher, "mulata fácil" está sempre a rodear o menino de engenho, seduzindo senhores e causando o ciúme e desgraça das donzelas brancas. Ao lado da mulata, a preta velha, ou a "negra de estimação", como escreve Monteiro Lobato, em Reinações de Narizinho (2014), serve à sociedade no espaço da cozinha, da ordenação e da limpeza, ela não tem família, o corpo é robusto, ideal para os afazeres pesados da casa, dedicada aos personagens brancos, sejam eles crianças, moços ou na maturidade. Ribeiro $(2015$, p.52) alerta que a literatura pode reforçar estereótipos, preconceitos, discriminações e perpetuar o racismo:

\footnotetext{
${ }^{1}$ Assim como demarcarmos o pertencimento racial dos escritores cujos textos analisamos, realizaremos, ao longo de todo o texto, a enunciação racial dos escritores aos quais contrapomos suas produções, principalmente com intenção de desmontar a ideia do branco, enquanto pessoa e condição racial, como narrativa universal.
} 
Quando a literatura propicia reforçar tal supremacia ela contribui para a morte da consciência negra. Matar a consciência é matar a dignidade humana nos negros. Daí que as reações a Lobato são frutos do engendramento de uma nova consciência a respeito da dignidade humana dos negros e dos mecanismos utilizados na sociedade como forma de negação de direitos. Desse modo, a literatura, a história, a medicina, a biologia, a antropologia, cada uma ao seu modo acaba contribuindo desde a invizibilização do negro até a criação dos estereótipos e estigmatização, cuja consequência é a negação da consciência, do ser e da dignidade.

No entanto, compreendemos que a literatura pode modificar e transformar a realidade, ao proporcionar ao leitor o conhecimento de diferentes vivências e experiências, possibilitando a ampliação de seu repertório, com o acesso a textos que tratem da temática e de autoria afro-brasileira, por isso a importância das representações de mulheres negras como as de Maria Firmina dos Reis e Luís Gama.

Em geral, nos textos do período em que escrevem os autores escolhidos, o século XIX, negros e negras eram personagens quase ausentes ou referidos ocasionalmente como parte da cena doméstica. Personagens mudos, desprovidos de uma caracterização que fosse além da referência racial, logo sem história ou profundidade.

David Brookshaw (1983), em seu livro Raça e cor na literatura brasileira, caracteriza algumas construções sobre as personagens negras, e no século XIX há a figura do "escravo ${ }^{2}$ nobre", em uma metáfora podemos defini-lo como o "negro de alma branca", que se sacrifica e aceita a submissão, narrativa sempre em paralelo a do "negro vítima". Mesmo que a intenção dos escritores seja a campanha abolicionista, a branquitude ${ }^{3}$ que os reveste impede a compreensão dos aspectos complexos das relações senhor-escravizado e, inclusive, molda a ideia do escravizado ideal que constroem em seus personagens. Quando não escravizado, a condição de afrodescendente carrega as características atribuídas ao escravo, caso do livro $O$ mulato, de Aluísio Azevedo (2005), no qual Raimundo, filho de um português com Domingas, uma mulher escravizada, diz em um momento de rompante de raiva:

\footnotetext{
${ }^{2}$ A substituição do termo corrente "escravo" pelo termo "escravizado" promove alterações semânticas do pressuposto de responsabilização e de opressão deste, no lugar do efeito de sentido de naturalização da condição cativa do primeiro (HARKOT-DE-LA-TAILLE; SANTOS, 2012). Mantemos aqui a denominação "escravo" quando se referindo à produção dos escritores e escritoras de literatura para demarcar a forma como compreendiam essa população negra que compunha o cenário brasileiro no período, por isso, quando se trata de análise das autoras do artigo, o conceito "escravizado" será empregado.

${ }^{3}$ Forma de ver e estar no mundo enquanto branco, com privilégios simbólicos reproduzidos na sociedade que concedem poder aos brancos e não são sentidos nem pensados como uma questão racial.
} 
- Não chores, minha flor... [...] Tens toda a razão... perdoa-me se fui grosseiro contigo! mas que queres? Todos nós temos orgulho, e a minha posição a teu lado era tão falsa!...Acredita que ninguém te amará mais do que te amo e desejo! Se soubesses, porém quanto custa ouvir cara-a-cara: "Não lhe dou minha filha porque o senhor é indigno dela, o senhor é filho de uma escrava!" Se dissessem: "É porque é pobre!" que diabo! - eu trabalharia! Se dissessem: "É porque não tem a posição social!" juro-te que a conquistaria, fosse como fosse!" É porque é um infame! um ladrão! um miserável!" eu me comprometeria a fazer de mim o melhor dos homens de bem! Mas um ex-escravo, um filho de negra, um - mulato! - E como hei de apagar a minha história da lembrança de toda esta gente que me detesta? (AZEVEDO, 2005, p. 251).

Raimundo, a personagem que dá nome ao livro $O$ mulato, um homem branco envolvido no movimento abolicionista do período, desejava ter a possibilidade de tornar-se branco por meio do apagamento de sua origem, para ser, então, digno de sua amada, Ana Rosa. Enquanto no poema "Minha mãe", de Luís Gama (2000, p. 75), a personagem, sua progenitora, é saudada por sua cor:

Era a mais linda pretinha,

Da adusta Líbia rainha,

E no Brasil pobre escrava!

Como está marcada sua condição de escravizada, trata-se de estar e não de ser, já que possui uma narrativa anterior a imposição de mão de obra escravagista, não a intenção de branquear-se, mas de positivar as experiências da população afrodescendente e negra. Ela não é vítima nessa narrativa, não carrega uma atitude resignada, assim como Joana, a personagem de Maria Firmina dos Reis (2004, p. 248), em "A escrava", que não suporta os castigos infringidos e foge: "Estava no serviço, coitada! Minha mãe caiu, desfalecida; o feitor lhe impôs que trabalhasse, dando-lhe açoites; ela deitou a correr gritando. E ele correu atrás [...]". E, mesmo em tempo de estar desfalecendo, toma para si a tarefa de falar de si, contar sua história:

Tenho a vista tão fraca... é a morte que chega [...]

- E quem é esse senhor tão mau, esse senhor que te mata?

- Então, minha senhora, não conhece o senhor Tavares, do Cajuí?

- Não, tornei-lhe com convicção: estou aqui há dois dias, tudo me é estranho; não o conheço. É bom que colha algumas informações dele? Gabriel me dará. - Gabriel disse ela - não. Eu mesma. Ainda posso falar. E começou.

- Minha mãe era africana, meu pai de raça índia [...]. (REIS, 2004, p. 254).

Não se constata nas representações femininas de Luís Gama ou Maria Firmina dos Reis a intenção de branquear a figura moral de negros e negras, 
facilitando-lhe, assim, a identificação simpática dos leitores da época, com os sofrimentos dos escravizados. A mulher abolicionista no conto de Maria Firmina dos Reis não concede voz à Joana e também não age como advogada em sua defesa, como a maioria dos textos abolicionistas do período. Joana fala e ao leitor cabe a tarefa de escutá-la, falar de si e de sua condição. Se no poema de Luís Gama (2000) não podemos ouvir sua mãe, o motivo é porque ela está muito tempo distante e trata-se de um exercício de rememorar, porém, sua rememoração não escolhe uma mulher sem expressão, e sim uma mulher atuante:

Ela fingia o martírio

Nas trevas da solidão.

Os alvos dentes, nevados,

Da liberdade eram mito,

No rosto a dor do aflito,

Negra a cor da escravidão.

Os olhos negros, altivos,

Dois astros eram luzentes;

Eram estrelas cadentes

Por corpo humano sustidas.

Foram espelhos brilhantes

Da nossa vida primeira,

Foram a luz derradeira

Das nossas crenças perdidas. (GAMA, 2000, p. 75).

Em contraposição ao "escravo demônio", ao "negro pervertido" e à ideia da raça negra inferior, como construído em A família Medeiros, escrito por Júlia Lopes Almeida (1892), uma mulher branca abolicionista, ou como persistiu no tempo chegando ao livro $O$ presidente negro (2012) escrito para o rodapé da Manhã, no ano de 1926, por Monteiro Lobato, escritor branco envolvido nas questões políticas da sociedade brasileira, percebemos nos textos escolhidos, " $A$ escrava" (REIS, 2004) e "Minha mãe" (GAMA, 2000), duas mulheres adultas que não são infantilizadas em suas ações, que não são tomadas por perversões, mas sim dotadas de caráter, a exercer, de diferentes formas, a maternidade.

Outro aspecto negado às narrativas com personagens negras, muito presente nesse período, está em, por exemplo, $O$ cortiço, escrito em 1890, por Aluísio Azevedo (2002), em que a personagem Rita Baiana, materialização da mulata sensual e de uma sexualidade animalesca, mesmo com "toda a intensa atividade sexual da mulata não traz consigo nem a gravidez nem a maternidade" (DUARTE, 2009, p. 9), sendo o corpo infértil em conversa estreita com uma ideia arianizante de extinguir a população afrodescendente. A hipersexualização dessas mulheres também é uma constante, independente de estarem ativas sexualmente ou não, caso da descrição da filha de Marciana, a menina Florinda, em $O$ cortiço: 
A filha tinha quinze anos, a pele de um moreno quente, beiços sensuais, bonitos dentes, olhos luxuriosos de macaca. Toda ela estava a pedir homem, mas sustentava ainda a sua virgindade e não cedia, nem à mão de Deus Padre, aos rogos de João Romão, que a desejava apanhar a troco de pequenas concessões na medida e no peso das compras que Florinda fazia diariamente à venda. (AZEVEDO, 2002, p. 16).

Esse é apenas um exemplo das muitas passagens da literatura onde mulheres negras são simplificadas a sexualidade aflorada, coisificadas em suas curvas e genitálias. Diametralmente oposto a isso, temos em "A escrava" (REIS, 2004) uma mãe que enlouquece por lhe terem tirado os filhos e que a própria mãe de Joana teve a vida encurtada ao saber da condição de escravizada da filha. A mãe, no poema de Luís Gama (2000, p. 76) é carinhosa e atenciosa com seus filhos, sorrindo-lhes e mimando mesmo que "As lágrimas que brotavam, eram pérolas sentidas, dos lindos olhos vertidas, na terra do cativeiro".

A maternidade, papel relegado às mulheres, e que está em constante processo de desromantização por parte de movimentos feministas e de mulheres aqui, nessas narrativas, na condição das personagens, que são mulheres negras -, converte-se em elemento de humanização de personagens que são, historicamente, não humanizadas nas narrativas difundidas como literatura brasileira, que, como já demarcado, possui cor, idade e gênero. Luís Gama e Maria Firmina dos Reis demonstram, nessas narrativas, como a autoria afrodescendente tem elementos próprios, homem e mulher, olham para essas mulheres negras por meio de suas vivências.

\section{Conclusão}

As mulheres negras representadas em "A escrava" (REIS, 2004) e "Minha mãe" (GAMA, 2000), fruto de uma escrita afro-brasileira, são representações construídas pelas vivências desses escritores afrodescendentes, que desafiam a lógica das representações que circulavam pela sociedade da época acerca da população negra. Acreditamos que evidenciar essas representações distintas da representação supostamente "hegemônica" é fundamental para ampliar a compreensão das realidades na sociedade, pois o caráter humanizante da literatura (CÂNDIDO, 2004) consiste nessa intenção de experienciar diferentes matizes, contextos, olhares das experiências sociais e, enquanto "Literatura", escapulir da evocação de narrativas com representações exclusivas do universo da branquitude, demarcar e pontuar uma literatura afro-brasileira é necessário.

Escolas são espaços de disputa e (re)construção de representações, e, enquanto instituição social onde ocorre organização e socialização de conhecimentos e de culturas, é também um dos espaços em que as representações positivadas sobre as mulheres negras devem ser difundidas para que possamos superar as representações estereotipadas e, de certo modo, acrescer para uma educação das relações étnico-raciais 


\section{REFERÊNCIAS}

ALMEIDA, Julia Lopes de. A família Medeiros. Rio de Janeiro: Companhia Editora $\quad$ Fluminense, $1892 . \quad$ Disponível em: $<$ https://digital.bbm.usp.br/handle/bbm/6776>.

AZEVEDO, Aluísio. O cortiço. Brasília, DF: MEC, 2002. Disponível em: $<$ http://objdigital.bn.br/Acervo_Digital/Livros_eletronicos/cortico.pdf $>$.

AZEVEDO, Aluísio. O Mulato. Brasília, DF: MEC, 2005. Disponível em: $<$ http://www.ebooksbrasil.org/adobeebook/omulato.pdf .

BRAZ, Júlio Emílio. Luís Gama: de escravo a libertador. São Paulo: FTD, 1991.

CÂNDIDO, Antônio. Direito à literatura. In: CÂNDIDO, Antônio. Vários escritos. São Paulo: Ouro sobre o Azul, 2004.

BROOKSHAW, David. Raça e cor na literatura brasileira. Porto Alegre, Mercado Aberto, 1983.

DUARTE, Eduardo Assis. Apresentação. In: REIS, Maria Firmina dos. Úrsula. Florianópolis, SC: Editora Mulheres; Belo Horizonte: PUC Minas, 2004.

DUARTE, Eduardo de Assis. Mulheres marcadas: literatura, gênero, etnicidade. Terra roxa e outras terras: Revista de Estudos Literários, Londrina, PR, v. 17-A, dez. 2009.

DUARTE, Eduardo de Assis. Por um conceito de literatura afro-brasileira. Terceira Margem, Rio de Janeiro, v. 14, n. 23, p. 113-138, jun. 2010. Disponível em: $<$ https://revistas.ufrj.br/index.php/tm/article/view/10953>.

DUARTE, Eduardo de Assis. Úrsula e a desconstrução da razão negra ocidental. In: REIS, Maria Firmina dos. Úrsula. Belo Horizonte: Editora PUC Minas, 2017. p. 209-236.

FREYRE, Gilberto. Casa grande e Senzala: formação da família brasileira sob o regime da economia patriarcal. São Paulo: Global, 2003. Disponível em: $<$ https://bibliaseliteraturas.files.wordpress.com/2014/04/casa-grande-e-senzalade-gilberto-freyre.pdf $>$.

GAMA, Luís. Primeiras trovas burlescas de getulino. São Paulo: Martins Fontes, 2000. Disponível em: <http://www.quilombhoje2.com.br/trovasLuísgama.pdf $>$.

HARKOT-DE-LA-TAILLE, Elizabeth; SANTOS, Adriano Rodrigues dos. Sobre escravos e escravizados: percursos discursivos da conquista da liberdade. In: Anais III SIMPÓSIO NACIONAL DISCURSO, IDENTIDADE E SOCIEDADE,3., 2012, Campinas. Anais... Campinas: Unicamp, 2012. Disponível 
$<$ http://www.iel.unicamp.br/sidis/anais/pdf/HARKOT_DE_LA_TAILLE_ELIZA BETH.pdf>.

LOBATO, Monteiro. O Presidente Negro. São Paulo: Globo, 2012.

LOBATO, Monteiro. Reinações de Narizinho. São Paulo: Globo, 2014.

REIS, Maria Firmina dos. A Escrava. In: REIS, Maria Firmina dos. Úrsula. Florianópolis, SC: Editora Mulheres; Belo Horizonte: PUC Minas, 2004.

REIS, Maria Firmina dos. Úrsula: Romance. Belo Horizonte: Editora da PUC Minas, 2017.

RIBEIRO, Rodrigo de Oliveira. Literatura e racismo: uma análise sobre Monteiro Lobato e sua obra. Geledes, São Paulo, 12 dez. 2015. Disponível em: $<\mathrm{https}$ ://www.geledes.org.br/literatura-e-racismo-uma-analise-sobre-monteirolobato-e-sua-obra/>.

SILVA, Régia Agostinho da. A mente, essa ninguém pode escravizar: Maria Firmina dos Reis e a escrita feita por mulheres no Maranhão. Leitura: Teoria \& Prática, Campinas, SP, v. 29, n. 56, p. 11-19, 2011.

Tatiana Valentim Mina Bernardes TatyMinaBernardes@yahoo.com.br

Zâmbia Osório dos Santos ZambiaOS@yahoo.com.br

Eliane Santana Dias Debus ElianeDebus@hotmail.com

Recebido em: 12 set. 2018

Aceito em: 5 dez. 2018

Publicado em: 29 dez. 2018 